\title{
Só Se Vive uma Vez: uma Reflexão aCERCa de Distintas ConcepÇões E Práticas do Uso de "Drogas"
}

\section{Taniele Cristina Rui ${ }^{1}$}

\section{Resumo}

Este texto pretende descrever e apreender concepções e práticas do uso de "drogas", bem como as noções de corpo, dor e prazer vinculadas a elas. Para tanto, são analisados três grupos distintos: ex-usuários que passam por tratamento de recuperação de "drogas", "meninos de rua" e estudantes universitários. Proponho que as diferenças entre os modos de conceber esses usos podem nos indicar caminhos para complexificar a questão das "drogas" na contemporaneidade, para o entendimento de hierarquias e classificações sociais que envolvem o consumo de "drogas" e a relação entre os grupos consumidores, bem como o modo que o tema é trabalhado pelas ciências sociais e/ou da saúde. Temáticas essas que ganham em profundidade quando o corpo (enquanto categoria de análise) assume centralidade na discussão.

Palavras-chave: uso de drogas, marcadores sociais, corporalidade.

\section{Abstract}

This is a description and presentation of practical conceptions related to the use of drugs and the notions of the body, pain and pleasures connected to this use. Three distinct groups were analyzed: former drug users under recovery treatment, "street children", and university students. Differences in uses can show us ways to question drugs in present days in order to understand social classes and hierarchies, the relationship between users, and how the issue is addressed by the social and health sciences. These are themes that can be deeply studied as a corpus of analysis when considered as the center of a debate.

Keywords: social use of drugs, markers, embodiment.

"É necessário olhar além do corpo para determinar

o que é normal para este mesmo corpo"

\section{G. Canguilhem}

${ }^{1}$ Aluna de pós-graduação da Unicamp. 


\section{INTRODUÇÃo}

ão diversas as formas de abordagem teórica, no interior das ciências sociais brasileira, que podem servir como guias para a análise da questão das "drogas" na contemporaneidade. Uma primeira via foi aberta por Gilberto Velho em seu trabalho pioneiro, Nobres e Anjos, escrito em 1975, mas só publicado em 1998. Nele, a questão dos "tóxicos"” foi tratada através do entendimento do contexto sócio-cultural, como parte de um estilo de vida e de uma visão de mundo que estariam associados a esse comportamento considerado, em princípio, como desviante. Outra grande ênfase é dada focando os seus aspectos legais e as polêmicas em torno da sua criminalização e/ ou descriminalização a partir do estudo sistemático do que veio a se tornar o Tráfico de Drogas $^{3}$. Ainda um outro caminho de pesquisa pode ser aberto se considerarmos o advento do processo de medicalização ${ }^{4}$ dos corpos e da vida e o aparato de repressão/ incitação que, como indica Eduardo Viana Vargas (2001), talvez seja a temática central para entender como as sociedades ocidentais criaram o próprio fenômeno das "drogas", seja produzindo-as em laboratório e/ou escala industrial, seja medicalizando e/ou criminalizando as experiências de consumo. Por último, o uso de "drogas" é também intelectualmente instigante por tratar-se de um fenômeno simultaneamente de ordem material e simbólica que coloca em jogo formas socialmente constituídas de agenciar modos intensivos ou extensivos de engajamento com o mundo (VARGAS, 2001). ${ }^{5}$

Construí minha investigação a partir do intercruzamento desta última perspectiva proposta por Vargas com a primeira abordagem "inaugurada" por Velho - as outras vias de pesquisa, ainda que essenciais para entender o cenário contemporâneo, não é o principal foco deste trabalho. Intercruzar essas duas perspectivas analíticas significa atentar tanto para a importância do entendimento dos contextos sociais em que o uso de "drogas" é enunciado e vivenciado, quanto para materialidade desta prática. Em suma, o desafio teórico é fazer com que (juntas) categorias como "corpo" e "contexto social" ganhem potencial explicativo para o uso de "drogas" na atualidade.

Antes de prosseguir, porém, um esclarecimento. Ao utilizar o termo "drogas"

\footnotetext{
${ }^{2}$ A palavra tóxico é usada pelo autor em todo o livro para referir-se ao sentido comum em que era empregada no Rio de Janeiro da época e se refere basicamente a maconha, cocaína, heroína, ácido, ópio, haxixe e alguns remédios como mandrix.

${ }^{3}$ Para essas questões ver os trabalhos de Antônio Serra (1985), Henrique Carneiro (2002), Marconi Andrade (2003), Thiago Rodrigues (2003), Alba Zaluar (2004).

${ }^{4}$ Sobre as controvérsias médicas em relação ao uso de drogas, ver o recente trabalho de Maurício Fiore (2004).

$5 \mathrm{Na}$ literatura brasileira, há ainda toda uma bibliografia, mais ligada à etnologia, que trata do uso de drogas em contextos rituais (LABATE; ARAÚJJ0, 2000; ARAÚJ0, 1999). Por limitações próprias, optei por não trabalhar com esta bibliografia no momento.
} 
durante a apresentação, refiro-me apenas a uma das conotações que a palavra tem, qual seja a que se refere ao conjunto das substâncias psicoativas de caráter ilícito no Brasil. Optei por utilizá-la porque a questão central deste texto é entender o que a categoria "drogas" aciona em termos de classificação e concepção das substâncias. Contudo, tal opção não me impede de ter uma postura crítica em torno da definição (farmacológica) mais aceita de droga atualmente: qualquer substância química capaz de, em contato com os corpos vivos, alterar seu funcionamento. Por si, esta definição, aparentemente objetiva, também é fruto de disputas classificatórias no interior das quais 0 ato de recusar ou aceitar determinadas substâncias como "drogas" é inseparável de juízos de valor. Assim, o uso do termo "drogas" entre aspas indica uma tentativa de problematizá-lo.

Voltando ao argumento, meu objetivo mais geral é entender concepções de prazer, dor e corpo vinculadas ao consumo de "drogas" entre jovens de diferentes segmentos sociais usuários ou ex-usuários dessas substâncias em contextos urbanos e não rituais. Com esse objetivo geral, pretendo apreender discursos frutos de contextos nos quais prazer, dor e corpo possuem significações específicas, construídas de acordo com a imagem que se tem da "droga" em cada um deles. Tenciono mostrar como essas noções são construções particulares de um contexto-sócio econômico singular e de um imaginário específico que possui relações próprias tanto com o circuito moral que circunscreve o mundo das substâncias psicoativas quanto com a necessária conexão entre as substâncias e o seu comércio.

Para esta publicação temática sobre "Antropologia da Saúde", selecionei mostrar o modo como sobretudo o "corpo" é concebido e produzido em distintos envolvimentos com "drogas" e como esta relação pode se colocar no tratamento que as ciências sociais e/ou da saúde conferem ao assunto. Nesse sentido, o interesse antropológico no assunto é entender como ele pode ser diferentemente nomeado, anunciado, formatado e praticado. Por sua vez, o tema se mostra ainda mais relevante quando consideramos o momento contemporâneo no qual o corpo adquire centralidade não só nas academias, no cinema, nas clínicas médicas e de beleza, mas inclusive e, sobretudo, na bibliografia publicada a seu respeito: há um crescente interesse no assunto, o que nos faz, de maneira geral, concordar com a idéia de David Le Breton (1990), segundo a qual o corpo é uma invenção da episteme ocidental e a noção mesma do corpo é um fato da modernidade.

0 texto de Marcel Mauss (2003a) sobre "as técnicas corporais", considerado um marco nas reflexões teóricas sobre o corpo nas ciências sociais, abriu caminhos para autores como Mary Douglas (1978) e Pierre Clastres (2003) chamarem atenção para o problema da corporalidade equacionado às representações coletivas que envolvem 
o corpo e que fazem dele o resultado de uma "construção social". No entanto, esses textos têm sido revisados por autores contemporâneos (CSORDAS, 1996; VARGAS, 2001; FRANGELLA, 2004; PONTES, 2004; SILVA, 2004) que os criticam por mostrar o corpo como superfície onde o mundo social se inscreve. Segundo eles, esta perspectiva resulta na renúncia de se levar em conta muitos processos que se desenvolvem com a materialidade dos corpos, mas que nem por isso são menos simbólicos. Este é o caso do consumo de "drogas". E é neste sentido também que Vargas (2001) considera que o consumo de "drogas" ilícitas, a partir do ponto de vista dos usuários, põe em jogo processos de alteração material e simbólica da percepção e envolve o agenciamento de modos singulares de encorporação $0^{6}$ e de subjetivação. Em outras palavras, isto equivale a dizer que o consumo de "drogas" oferece um campo privilegiado para problematizar a partilha entre a materialidade dos corpos e imaterialidade dos espíritos tão dominante na teoria social.

Empiricamente, optei por realizar o estudo tendo como principal marcador o recorte de "classe social, estrato ou grupo de status". Tal opção se deu especialmente após a leitura de Nobres e Anjos. A citação é longa, mas necessária:

Tendo realizado a pesquisa numa grande metrópole, numa sociedade estratificada, tive oportunidade de verificar que os tóxicos são utilizados e reprimidos de forma bastante diferenciada, basicamente em função da classe social, estrato ou grupo de status a que pertença o consumidor. Desta forma, o tóxico não só tem significados diferentes em função do grupo que o utiliza, como sua utilização pode ser interpretada por não consumidores, acusadores potenciais e autoridades de maneira diferente, provocando reações particulares. Mais ainda, embora possam ser estigmatizantes em termos de uma cultura dominante oficial, os tóxicos são manipulados como símbolos de prestígio não só internamente aos grupos estudados, mas como forma de marcar distâncias em termos de relacionamento entre grupos sociais ou estratos sociais distintos. (...) Na medida em que [o tóxico] se incorpora ou que é compreendido não isoladamente, mas como sendo um item de um estilo de vida, vai ser mais um elemento que contribuirá para o estabelecimento de hierarquias internas a uma classe. (VELHO,1998, p. 204-205)

\footnotetext{
${ }^{6}$ Por falta de um termo específico em português para traduzir a idéia implícita no termo embodiment (CSORDAS, 1996), muitos autores que tratam do tema recorreram ao neologismo encorporação, ao invés dos termos incorporação ou encarnação já existentes. Isto porque, "incorporar" tem a ver com algo que existe antes ou fora do corpo e a ele se junta, ao passo que "encorporar" diz respeito a dar ou tomar corpo, corporalizar, materializar e não supor o dualismo corpo/mente implícito nos vocábulos "incorporar" e "encarnar". Para essa discussão ver Vargas (2001); Simone Frangella (2004) e Daniela A. Silva (2004).
} 
No que diz respeito ao intercruzamento corpo e classe social, o trabalho de Luc Boltanski (1979) é uma referência. Para este autor, os usos dos corpos, bem como suas capacidades de resistência à dor, variariam de acordo com as classes sociais consideradas, assinalando ainda que o estabelecimento de uma relação reflexiva com o corpo é pouco compatível com uma utilização intensa do corpo: é como se o crescimento da consciência do corpo e do interesse dedicado a ele estivessem em correlação com uma espécie de inversão de suas funções econômicas. No entanto, tal relação não se dá de forma automática. Há uma mediação entre o contexto intelectual, histórico, econômico e social em que a pessoa está inserida e as concepções de corpo que podem ser feitas e produzidas a partir daí, ocasionando e traduzindo repulsas, desejos, gostos e aversões. É nesse sentido que questões gerais a respeito da especificidade contemporânea, do papel que as "drogas" têm no mundo de hoje, bem como a importância que os corpos adquirem na atualidade não são questões menores. Ao contrário, elas são essenciais para nos fazer entender como as "drogas" são encorporadas em trajetórias particulares de dor, prazer e desejo. Ainda que não as determine, são essas categorias cultural e socialmente específicas que configuram, conformam e se refletem nestas experiências.

Metodologicamente, optei pelo trabalho de campo e pela etnografia, tão caros ao ofício de antropólogo. Como minha intenção era buscar diversas interações possíveis de envolvimento com "drogas", fui atrás delas em diversos locais. Realizei trabalho de campo com adolescentes e jovens em situação de rua ${ }^{7}$ da cidade de Campinas, tão conhecidos como meninos de rua ${ }^{8}$, em uma clínica de tratamento de "drogas" e com estudantes universitários da Unicamp. Contudo, mesmo tentando percorrer diversos ambientes, sei que não darei conta nem de "tudo" e nem do "todo" e que não sou capaz de apreender todas as interações possíveis. Mas com o que observei até aqui, consegui um material razoável que me permitiu levantar algumas questões e problemas. Vamos a eles.

\footnotetext{
${ }^{7}$ É importante dizer que há uma disputa classificatória no que tange à nomeação desses adolescentes que permanecem nas ruas praticamente o dia todo, como afirma o trabalho de Frangella (1996): "tais crianças ou adolescentes são considerados, pelas instituições que atendem crianças carentes, sujeitos 'em situação de rua', ou 'em situação de risco', ou seja, estão de passagem pela rua, e são carentes das prerrogativas do Estatuto da Criança e Adolescente (ECA): boa alimentação, saúde, escola, moradia, atenção dos pais. Por outro lado, na classificação das instituições punitivas e de boa parte da imprensa, são chamados de 'menores de rua', ou 'infratores' - aqui a imagem do perigo é reforçada. De qualquer forma, tais classificações são feitas a partir dessas crianças e adolescentes nas ruas do centro da cidade, explicitando uma realidade oriunda dessa relação rua/criança" (FRANGELLA, 1996, p. 10).

${ }^{8}$ Segundo Gregori, a partir da expressão "meninos de rua" foi identificado e nomeado um segmento social que, "mais do que a mera familiaridade ou o convívio esporádico com a rua, faz dela o lugar que ordena seu cotidiano, suas relações e sua identidade" (GREGORI, 2000, p. 15).
} 


\section{Corpos, Corpos, CoRPOs....}

Sendo o corpo a entrada por excelência das drogas, via nariz, boca, ânus ou veias, é ele quem "dá bandeira" ou que sinaliza o uso de "drogas"; é ele que expõe os benefícios ou os danos desse uso; é através dele que muitos adquirem ou doam "drogas" e é sobretudo por meio dele que são abertas as "portas da percepção". Há desde os sinais visíveis como olhos vermelhos, pupilas dilatadas, dentes manchados, marcas que indicam o uso de seringas, nariz sangrando, dedos indicador e polegar amarelados, mandíbulas deslocadas, pernas que tremem, até aqueles sinais imperceptíveis que se referem às descrições de sensações dolorosas internas, interrupção da menstruação no caso de algumas mulheres, "cabelos e pele sem brilho" ou "pele muito bonita, quando uso LSD". "Drogas" que correm nas veias, que chegam aos pulmões, que dão um "tuim" no cérebro, que provocam dor ou que anestesiam. Há também os sinais referentes ao cuidado com o corpo. Muitos dizem que param de tomar banho e associam o uso de "drogas" com a sujeira, param de se preocupar com a sua aparência, não se olham no espelho, não penteiam cabelo. Emagrecem, mas não percebem ou comem muito, quando dá "larica". Corpos que podem ser picados em todos os lugares: nos braços, nas pernas, nos pés, no pescoço.

É pelo corpo e pelos seus sentidos que tato, visão, olfato, paladar e audição ganham novos aspectos bastante distintos dos percebidos sem a "droga". Como me disse Vivian, internada em uma clínica de recuperação de "drogas" e "limpa" por dois meses, "quando chorava e engolia a lágrima ela tinha o gosto da droga. Só agora vi que ela é salgada". Corpos que vêem movimentos ou mais rápidos ou mais lentos, que vêem distorcido o que existe, que vêem até o que não existe. Corpos que ouvem o que cotidianamente não se ouve. Como me disse um estudante da Unicamp, que fez uso de LSD: "coloquei a mão em uma árvore e senti todo o movimento da seiva. Será que é essa a percepção verdadeira ou ela é fruto da droga? Não consegui ter uma resposta". Corpos que se excedem, que se "overdosam", que experimentam. Corpos que indicam a hora de parar e que quando param também pedem pela "droga", torcem-se, vomitam, choram, esperneiam, aquietam-se. Corpos que se oferecem a outros em troco de "drogas", corpos que pedem, que querem, que espancam com o fim de conseguirem "drogas". Corpos marcados, testados, avaliados. Corpos movidos a "drogas", que cheiram "droga". Corpos que controlam a "droga". Corpos que se mostram, que se escondem. Corpos que morrem, que quase morrem. Corpos dóceis, indóceis, sãos, não sãos.

Se há um fator de individuação, este está no corpo, já disse Durkheim. Ao introduzir a discussão das "drogas" a partir do corpo, o fiz porque acho, a partir das minhas observações, que se há algo de específico neste fenômeno é a problemática da 
corporalidade nele envolvida. É ela quem dá o limite para que o "plano-droga" (DELEUZE; GUATARRI, 1997) possa ter bom êxito. Mas mesmo esta aparente materialidade e autonomia dos corpos - e este é o ponto - pareceu-me indissociável do contexto histórico, cultural, econômico e social no qual esses corpos estão inseridos. Ou seja, em nenhum dos lugares que freqüentei e com nenhuma das pessoas que entrevistei consegui obter respostas que não estivessem relacionadas com a forma pela qual estas pessoas concebem o mundo, e com o lugar que elas ocupam na estrutura social. Isto significa que ainda que a questão das "drogas" coloque em xeque "formas intensivas ou extensivas de engajamento com o mundo", essas não estão indissociadas de contextos materiais e simbólicos bastante particulares. Portanto, os corpos que sentem os efeitos do uso contínuo de "drogas", os sentem a partir de um lugar específico. E é este lugar que faz toda a diferença entre as distintas maneiras de compreensão do que significa a "droga" tanto em cada um desses grupos, como no interior mesmo das ciências sociais e/ou da saúde, como pretendo mostrar.

Tendo em vista, o espaço curto deste artigo, farei um breve resumo da etnografia, visando colocar algumas questões ao final.

\section{Na Unicamp, os "Novos Nobres"}

De modo geral, há entre os estudantes universitários da Unicamp uma idéia de que os corpos devem ser usados como veículos para o auto-conhecimento e para a descoberta do verdadeiro "eu". Nesse sentido, o uso de "drogas" e o estado emocional da pessoa estão intimamente ligados. Assim, usar "drogas" (principalmente maconha e LSD) é bom porque "relaxa", porque traz "paz interior", porque faz "ver o mundo de outro jeito", porque "te abre a cabeça", porque faz ver "que há muitas coisas na vida que valem a pena, e outras com as quais nem vale a pena se preocupar", porque "mostra o que você realmenteé, mas que as máscaras que você usa no dia-a-dia não te permitem ser", porque "maconha potencializa o seu estado de espírito: se você estiver depressivo, você fica mais depressivo; se você estiver alegre, você fica mais alegre", porque "quem nunca usou ácido, não viveu".

0 uso geralmente se dá em grupo, no interior da Universidade, quando se juntam para discutir assuntos de interesse geral ou em festas em casas de amigos, as chamadas repúblicas, onde se reúnem também para dançar e conversar. Quando estão sozinhos, normalmente usam no fim do dia ou durante a madrugada, dependendo do ritmo da pessoa. Usam sós quando querem "um tempo para si", "um momento meu", "um tempo onde não penso em nada além daquilo que realmente me preocupa no mundo", "uma hora em que fico cá com meus pensamentos". São pessoas cuja capacidade 
intelectual para pensar e refletir sobre o mundo é bastante grande, alguns se dizem "sensíveis", outros "diferentes", outros ainda "esclarecidos". Grande parte deles faz ou já fizeram análise. Embora esteja presente um caráter lúdico, de diversão e de prazer, este não está descolado de coisas que consideram fundamentais: no caso, "conversas interessantes sobre idéias".

Em termos econômicos, numa visão geral, fazem parte do que no senso comum chamamos "classe média". No geral, os pais são bem instruídos. Mesmo quando não possuem diploma superior, a preocupação com os estudos dos filhos sempre esteve presente. São jovens que possuem entre 19 e 28 anos? e que, ainda que consigam "um dinheiro" por conta própria, contam com algum tipo de apoio financeiro dos pais, principalmente para o pagamento das contas de aluguel, água, luz, telefone. Quando não guardam o próprio dinheiro, gastam-no em comida, roupas, sapatos, livros e viagens. Muitas viagens. Fernanda, uma entrevistada, trabalha seis meses por ano. Junta dinheiro e passa outros seis meses viajando. Entre as principais viagens, foi para Búzios fazer curso de mergulho e para os Estados Unidos fazer cursos de gastronomia. Todos eles praticamente falam uma segunda língua e/ou já foram para o exterior.

Esses trazem no corpo as marcas de suas experiências sociais. A grande maioria é branca, tem cabelos e peles muito bem tratados. Ainda quando fazem o estilo "hippie" suas roupas têm um estilo próprio e, no geral, são caras se comparadas com as que os jovens do segundo grupo (ainda a ser apresentado) utilizam. Andam com a cabeça erguida e possuem sempre uma atitude corporal de abertura para o mundo. Seus pés, suas unhas e suas roupas são limpos. Tomam banho diariamente e no geral, dormem e comem bem. Quando perguntados sobre alguns dos efeitos do uso contínuo de "drogas" sobre o corpo, referiram-se ao fato de o cabelo e a pele estarem mais opacos, os dedos e dentes amarelados; e à falta de concentração para as aulas. Fatores esses que são compensados pela sensação de euforia, de bem estar e de "conforto espiritual" que a "droga" proporciona.

Nesse contexto, o uso de "drogas" está ligado a uma postura crítica e não "careta" em relação a determinados valores da sociedade ou a determinadas formas de comportamento e de usos do corpo. A questão da "intensidade" tão bem teorizada por Vargas está bastante presente ${ }^{10}$. Usar "drogas" tem a ver com "estar aberto" para as experiências, para as sensações e para a "vida" no sentido geral. Significa "ver que há

\footnotetext{
"Esse dado referente à idade é bastante interessante, pois todos esses entrevistados se consideram "jovens" - o que mostra que o conceito de juventude, mais que ser uma experiência cronológica, é uma experiência sociológica.

${ }^{10}$ Como me disse Fernanda depois de já termos feito a entrevista e depois de conversarmos várias vezes sobre 0 assunto. Um dia ela me parou e disse: "acho que encontrei a resposta para o porquê de eu andar só com pessoas que usam drogas: é pelo tipo de vida intensa que elas levam. E eu gosto da intensidade".
} 
muito mais coisas entre o céu e a terra" e que "não estamos aqui de passagem". Todos já tiveram bad trips, "sentimentos ruins", "sensação de quase morte". No entanto, esses aspectos dolorosos da experiência são ressignificados como indicador dos limites de até onde se pode ir com o uso. Funcionam, portanto; como fator capaz de indicar a "dose" certa e a substância adequada.

\section{Na RuA}

Entre os adolescentes em situação de rua da cidade de Campinas, as drogas mais usadas são maconha, crack, cola e algumas misturas como "mesclado" (cigarro + maconha), "pitilho" (cigarro + crack), "cogumelo" (cigarro + farinha). 0 uso de maconha é normalmente uma atividade coletiva, enquanto o uso das outras "drogas" pode ser tanto coletivo quanto individual. Mais de uma vez observei algum deles juntar cinco reais que "dá pra uma pedrinha" e em seguida "sumir" por quinze, vinte minutos. 0 uso entre esses adolescentes se dá rotineiramente, regado a idas e vindas a um dos principais semáforos da cidade de Campinas ${ }^{11}$. Junta-se um dinheiro, que varia entre três e dez reais, vai-se de ônibus até à "favela"12 "fumar um" e volta. Às vezes, um se encarrega de ir até à "favela" e traz para os outros. Quando isso acontece, eles fumam numa praça a quinhentos metros dali e em dez, quinze minutos já estão de volta ao semáforo.

Eles têm entre 12 e 23 anos. A chegada dos 18 anos é vivida com bastante aflição, porque chegam à maioridade penal e podem responder processualmente. Essa demarcação faz com que, normalmente, sejam os menores de 18 anos os que buscam e os que "seguram" a "droga", até ela ser ou dividida a todos ou ser repassada ao comprador. Aqui, tráfico e uso são realidades que se confundem e se há algo que une esses jovens, esse algo é o medo e a desconfiança da polícia. Seus corpos são marcados pelo emagrecimento constante, dentes muito manchados, sujeira, principalmente das unhas das mãos e dos pés. São muitas as tatuagens que recobrem seus corpos. Feitas artesanalmente por amigos e/ou por eles mesmos, principalmente em períodos que

\footnotetext{
11 Trata-se do conhecido semáforo da Norte- Sul, uma grande via da cidade de Campinas que, como o próprio nome indica, liga os dois extremos (Norte e Sul) da cidade. Essa via fica embaixo de um viaduto chamado por muitos de Laurão. Como é sabido que nesse lugar há vários adolescentes em situação de rua, a prefeitura de Campinas junto a uma instituição da cidade, construíram embaixo desse viaduto uma casa que serve de referência aos adolescentes. Nesta casa, trabalham dois educadores de rua que ficam à disposição dos adolescentes tanto para realizarem atividades lúdicas como para resolver problemas como feitura de documentos, cumprimento de medidas judiciais, referenciamento para abrigos, intermediação com a polícia e/ou com comerciantes locais, etc.

${ }^{12}$ Favela" é o termo que eles usam para referirem-se ao local onde conseguem drogas. Do que consegui apreender até esse momento da pesquisa, tratam-se de duas favelas da cidade de Campinas: 0 Jardim Itatiaia e o Jardim São Fernando. Mas esse termo é também equivalente à "boca", e não sinaliza um local específico.
} 
passaram por instituições fechadas. No geral, usam roupas velhas. As roupas novas e os tênis são moeda na troca por "droga". Mais de uma vez observei tênis novos serem trocados por "cinco pedras".

Eles não possuem lugar fixo para dormir. Às vezes em casas abandonadas ou em frente a estabelecimentos comerciais. Quando conseguem um bom dinheiro dormem em pensões da cidade. A diária custa 12 reais com café da manhã. Normalmente, comem uma vez ao dia um marmitex que custa $\mathrm{R} \$ 4,50$. Dependendo do dinheiro que conseguirem ou das doações que recebem no farol, comem mais. Não tomam banho diariamente. Suas narrativas com relação a contravenções legais são constantes. Observei muitos chegarem com celulares roubados que rapidamente foram passados "para frente". Sem dúvida, a "droga" é centralidade na vida da maioria desses jovens, na medida em que ela baliza uma rotina. Trabalhar no semáforo, realizar pequenos furtos e roubos, vender "drogas", fazer um serviço pra alguém, adquirir bens que possam ser trocados por "drogas", bem como circular pela cidade figuram como as principais atividades diárias. Há uma regra de solidariedade: quem tem sempre divide com os outros. Isso cria vínculos no momento mesmo em que cria dívidas. Ao fumar a "droga" de um amigo, automaticamente entram no bau: a oferta terá de ser retribuída. Falam muito sobre "drogas". Sobre a preparação, sobre como conseguem, sobre venda, sobre a "nóia". Mas sempre que pergunto o porquê do uso, não consigo respostas. "Porque sim" é a mais comum delas. Usa-se "porque gosto", "porque uso há muito tempo", "porque é bom", "porque sim". Não há mais nisso: gosta-se e pronto. Quase que uma bricolage feita a partir e através do corpo. Usam todos os dias, mas não se consideram "viciados". Insistem em dizer que quando quiserem, conseguem parar. Mas não querem.

\section{A Instituição}

No interior da instituição de tratamento em que realizei etnografia, os ex-usuários de "drogas" em processo de recuperação se autodenominam como pertencentes a uma mesma "família" cujo interesse está voltado para acabar com sua "adicção". Influenciados pelo discurso religioso da instituição, (discurso esse que, em si, já torna problemática a idéia de recuperação - mas isso é uma questão que não tratarei neste texto) o uso de "drogas" é considerado uma doença que deve ser tratada. A cura se daria através da oração e do trabalho. Ainda que muitos desses internos não concordem com a visão da instituição, para estar "dentro do programa" é preciso primeiro admitir que se perdeu o controle da própria vida e que se deixou levar pela "droga", admitir que é doente, que precisa de ajuda e que sozinho não consegue se recuperar. É baseado na idéia de impotência do corpo e da mente perante as "drogas" que o discurso da instituição 
é construído e que a idéia de doença está assentada. Neste contexto, é preciso um esforço corporal grande e intenso. 0 trabalho braçal de limpeza do local torna-se terapia, "laborterapia": o corpo vai se "limpando" através do suor, e a mente sendo ocupada pelas orações e pelo contato espiritual com Deus.

Esta instituição de tratamento, uma das mais conhecidas no Brasil, é interessante porque funciona a partir de recursos privados e públicos. Na prática, isso significa que ela recebe para internação tanto pacientes que podem pagar pelo tratamento, quanto pacientes que são indicados por determinação judicial ou referenciamento de outras instituições da cidade. No primeiro grupo, estão pessoas cujas famílias arcam com os custos do tratamento e no segundo, estão pessoas que são encaminhadas para tratamento na instituição por terem cometido atos infracionais ou que não possuem lugar de moradia e estão envolvidas com "drogas". Tal configuração da instituição impõe o convívio de grupos distintos material e simbolicamente, por pelo menos seis meses, em torno da temática das "drogas". A instituição atende tanto homens quanto mulheres, embora os homens sejam maioria.

Nesse sentido, grupos que jamais se encontrariam - ou se encontrariam apenas na venda e na compra de drogas (nas negociações do tráfico) - são obrigados a conviver durante o período de internação. Assim, distintas trajetórias de envolvimento com "drogas" se encontram em um mesmo lugar. Este encontro dá origens as mais diversas relações. Pessoas tão diferentes são reconhecidas como fazendo parte de uma mesma "família" por não quererem mais usar "drogas", ao mesmo tempo em que sua condição de "adictos" os fazem os únicos autorizados a entender o que o outro está sentindo, "só um adicto entende outro adicto". Criam-se laços pessoais que "vão levar para toda a vida". Há um caráter performativo das relações criado a partir do cotidiano da clínica.

No interior desta instituição, há um direcionamento no olhar lançado sobre as "drogas" que privilegia a lembrança dos aspectos negativos e dolorosos da experiência com as "drogas", em detrimento dos seus aspectos positivos. É essa lembrança tornada tempo presente que garante a continuidade do tratamento e a garantia da "sobriedade", de outra maneira impensável.

\section{Comentários}

0 mais interessante, para a problemática que proponho discutir, é tentar entender como vivências tão distintas podem ser articuladas em torno da experiência com "drogas", enquanto uma categoria que, como procurei mostrar, difere de acordo com o contexto investigado. 0 que essas breves etnografias indicam? Contextos diferentes, formas de uso e envolvimento completamente diferentes? De um lado sim e, portanto, 
parte do entendimento da questão deve-se ao estudo de Gilberto Velho (1998) e à sua explicação, segundo a qual isso que aparentemente se considera "mundo das drogas" nada tem de monolítico ou homogêneo e é falsa a afirmação de um sentimento de solidariedade existente entre as pessoas que usam "tóxicos". Segundo ele, seriam as diferenças internas em termos de "droga" utilizada, faixa etária, características de estrato social, que vão marcar fronteiras bastantes nítidas (o caráter prescritivo das relações tematizado por Sahlins, 2003). Não há, portanto, uma fronteira única, "mas uma constelação de grupos que têm em comum uma atividade clandestina e ilegal" (VELHO, 1998, p. 16). Foi diante dessa constatação que um dos objetivos centrais do autor passou a ser verificar até que ponto o uso de "drogas" estabelece fronteiras significativas dentro da sociedade estudada, a que estilo e visão de mundo ele está associado.

Nessa interpretação, não há como dissociar o corpo que usa "drogas" das suas experiências sociais. Assim, o corpo simboliza o "eu" num contexto em que a "droga" e o corpo são veículos para o autoconhecimento e uma atitude crítica e não "careta" em relação a determinados valores sociais. 0 corpo emagrecido e sujo simboliza uma experiência com drogas marcada pela "rua", onde não há uma preocupação no sentido de buscar uma justificação para o uso: usa-se e fim; com todas as conseqüências decorrentes disso. 0 corpo que sua na clínica, o faz para recuperar-se dos abusos de antes, quando se consumia "droga" em abundância.

Mais que isso, também as concepções de dor e prazer ganham significações locais. No contexto universitário, há uma ênfase dos aspectos positivos e prazerosos da experiência, em detrimento dos seus aspectos dolorosos que, por sua vez, funcionam como indicador da dose certa para não ter "viagem errada". Ao contrário da clínica que, para seguir com o seu propósito da abstinência total de "drogas", precisa fazer com que os internos se apeguem às suas experiências dolorosas com o intuito de delas se livrarem, e trilharem suas vidas de um jeito diferente, isto é, sem "drogas". Na rua, as relações entre prazer e dor são mais complexas, uma vez que são menos verbalizadas e uma vez também que, de um lado, esses adolescentes precisam lidar com o discurso conservador das instituições que o cercam; e de outro, lidar com o fato de que usar "drogas" é atividade central numa dinâmica do cotidiano em que as "drogas" são marcadores temporais das atividades diárias.

Esta relação entre concepções de corpo, dor e prazer e diferentes contextos de uso de "drogas" é, como já escrito, central para entendermos as variedades presentes num universo tão heterogêneo e que portanto problematiza qualquer tentativa de estabelecimento de "grupos", bem como possibilita relativizarmos as formas de uso e interação com as substâncias. No entanto, essa abordagem ainda não leva em conta 
outros aspectos tão importantes dessa experiência. E é justamente neste ponto que pretendo, a partir deste momento do texto, centrar minha apresentação, embora saiba que 0 trabalho de campo pode indicar muitas outras questões. Explicitamente aqui, pretendo chamar atenção para as lacunas de uma abordagem focada apenas no entendimento do contexto sócio-cultural onde o uso de "drogas" se localiza. Isto porque, não se pode desconsiderar que se trata de uma prática que envolve riscos físicos e sociais e, portanto, o recurso a essas práticas, e não a outras, coloca problemas específicos que o princípio da influência do meio social por si só não dá conta.

E aqui volto à questão da corporalidade pois ainda há uma materialidade, no limite dada pelo corpo, que faz com que algumas pessoas façam uso abusivo destas substâncias, chegando mesmo a ocasionar processos de autodestruição muito sérios como os internos da clínica comprovam. E isso não parece ser uma questão de maior ou menor informação com relação à substância. No interior da instituição de tratamento, tive contato com muitas pessoas cujo plano fracassou. Não cabe a mim dizer se estas pessoas são dependentes ou não, mas muitas delas reconhecem que, em algum momento de sua trajetória, falharam. Nos dizeres de Deleuze e Guatari, optaram pela "má molécula". Entre os adolescentes em situação de rua, com todas as condições econômicas desfavoráveis, posso afirmar que a "droga" se torna um problema mais devido ao estabelecimento de dívidas que geram prestações de favores que sempre geram outras prestações e assim infinitamente do que um problema físico de dependência. Já observei muitos que passaram a usar eventualmente porque "enjoaram", ou que foram para instituições da cidade onde o uso de "drogas" não é permitido e não fizeram uso durante esse tempo. Outros, entretanto, emagrecem a cada dia, cada vez "caindo mais no buraco que no barato". Com os estudantes universitários, a situação não é diferente. Muitos pararam de usar por um tempo "porque de repente, toda a minha vida estava voltada para isso" ou "porque vi que estava perdendo o controle". Enquanto outros usam "numa boa", "pra relaxar", "pra esquecer", pra ficar consigo mesmo.

Há então uma questão, no limite dada pela própria corporalidade e pela própria natureza da substância, queé a de como abordar, em termos antropológicos, o problema da dependência química. Isto porque, de maneira geral, na bibliografia consultada que trata do assunto (VELHO, 1998; MACRAE; SIMÕES, 2000; VARGAS, 2001), essa questão não aparece, ou se aparece, está sempre em segundo plano. Por isso a questão de se perguntar acerca das concepções de dor e prazer é interessante. Isto porque, a ênfase desta bibliografia certamente recai na idéia de prazer, de controle, de etiqueta e de um uso discriminado em relação às "drogas", mesmo quando descrevem as bad trips (as dores), pois estas funcionariam como o limite de até onde se pode ir. Ao optar pela 
etnografia em contextos tão diversos, e para as relações entre corpo, prazer e dor, a minha intenção foi justamente chamar a atenção para o que parece não ser uma questão dessa bibliografia, uma vez que são experiências materiais diferentemente significadas pelos distintos contextos sociais.

Busquei comparar, ainda que por emblemas e sabendo que tais divisões são bem mais complicadas, universos sociais distintos tanto no que tange ao lugar ocupado na estrutura social, quanto e principalmente em termos culturais e educacionais. Ao fazer isso, busquei fazer irem juntos grupos que provavelmente não se encontrariam, em função das distâncias sociais dadas. E que, justamente pelas diversas formas de se envolver e conceber as "drogas" são, em muitos momentos, naturalizados uns como objetos das ciências sociais (os controlados, os que conseguem entender a relação estabelecida entre as drogas e a busca "pelo eu verdadeiro"), e "outros" ("viciados" que se deixam levar pela "droga") como objetos de estudo e intervenção da Saúde Pública.

Indo mais além: colocar em contato, nem que seja textualmente, grupos tão distintos pode nos ajudar a refletir sobre a problemática das "drogas" na contemporaneidade? Já sabemos que o cenário das "drogas" não se restringe ao "morro", e ao que se tornou o Tráfico de Drogas. Também sabemos que há um comércio que envolve muito dinheiro e que, provavelmente, é a classe média que sustenta esse comércio e que faz ele ser vantajoso financeiramente. Sabemos ainda que se quisermos uma explicação teórica e potencialmente relevante, temos de atentar para todos estes fatores e relações envolvidos, bem como problematizar a "partilha moral" que classifica algumas substâncias como "drogas" e outras não, e criticar o que chamamos "modelo proibicionista"13.

Mas mais que isso: acredito que precisamos encontrar uma via analítica que possa fazer com que usos tão diferentes sejam igualmente inteligíveis; e não abordar a questão de uma forma que às vezes parece cair em visões etnocêntricas que julgam alguns usos como melhores, mais racionais e portanto, mais justificados que outros. Chegamos então ao principal problema do desvio: que é o problema de quem pode ou não, quem tem legitimidade ou não, quem tem segurança ou não de exercer

\footnotetext{
13 "Modelo proibicionista" é o nome dado ao resultado de "um sistema de interações entre, de um lado, as atividades dedicadas à produção e comércio de algumas substâncias psicoativas e, de outro, às atividades destinadas a controlar e conter essa produção e comércio" (ANDRADE, 2003, p. 86). Questionar esse "modelo" implica em procurar "os mecanismos sociais que fizeram dessas substâncias o motivo de uma ameaça real às sociedades contemporâneas e, mais intensamente, à sociabilidade urbana [...]. Assim, partimos do pressuposto de que a criminalidade e a violência observadas em torno das drogas não decorrem de qualquer característica intrínseca a elas, mas sim da forma como foram e estão sendo agenciadas pelo modelo proibicionista" (ANDRADE, 2003, p. 84).
} 
determinadas formas de interação social. No caso específico das "drogas", isto se traduz em quem consome, em qual contexto e de que modo. Nessas "disputas" classificatórias entre grupos consumidores de "drogas", o que está em jogo é também quem detém a possibilidade de vida na "fantasia" e a existência da experiência diversificadora, em que o corpo aparece como a grande porta de entrada. Assim, ao escolher pesquisar os três contextos apresentados, o fiz porque queria ter contato com pessoas que tinham distintas experiências sociais, que traziam no corpo e através do corpo (bem como nas suas concepções a respeito de dor e de prazer) o modo em que percebem o mundo e estão nele inseridos e com isso, tentar complexificar explicações que vão em uma ou em outra direção. À epígrafe de Canguilhem, eu acrescentaria: é preciso olhar não só além mas também aquém do corpo para determinar o que é normal para este mesmo corpo. Mas talvez não seja só uma questão de interior e de exterior. A questão das "drogas" parece nos mostrar que é mais complicado que isso.

\section{REFERENCIAS}

ANDRADE, Marconi Tabosa. Política de Proibição às drogas: solução ou problema? 2003. Dissertação (Mestrado em Antropologia) - Unicamp/IFCH, Campinas, 2003.

ARAÚJO, Wladimyr Sena. Navegando sobre as Ondas do Daime: história, cosmologia e ritual da barquinha. Campinas: Ed. da Unicamp, 1999.

BOLTANSKI, Luc. Os usos sociais do Corpo: as classes sociais e o corpo. Rio de Janeiro: Graal, 1979 .

CARNEIRO, Henrique. As necessidades humanas e o proibicionismo das drogas no Século XX. Revista Outubro, IES, São Paulo, v.6, p. 115-128, 2002.

CLASTRES, Pierre. Da tortura nas Sociedades Primitivas: a Sociedade contra o Estado. São Paulo: Cosac\&Naify, 2003.

Csordas, Thomas. Introduction: the body as representation and being-in-the-world. In: Embodiment and experience. London: Cambridge University Press, 1996.

DELEUZE, Gilles; GUATARI, Félix. Devir-Intenso, Devir-Animal, Devir-Imperceptível. In: . Mil Platôs. Capitalismo e Esquizofrenia. São Paulo: Editora 34, 1997. v. 4.

DOUGLAS, Mary. Los dos cuerpos. In: Símbolos Naturales: exploraciones en cosmologia. Madrid: Alianza, 1978.

FIORE, Maurício. Controvérsias Médicas e a questão do uso de "drogas". 2004. Dissertação (Mestrado em Antropologia Social) - USP/FFLCH, São Paulo. 
FRANGELLA, Simone Miziara. Capitães do asfalto: a itinerância como construtora da sociabilidade de meninos e meninas "de rua" em Campinas. 1996. Dissertação (Mestrado) IFCH/Unicamp, Campinas.

FRANGELLA, Simone Miziara. Corpos urbanos em trânsito: construções corporais na experiência urbana contemporânea, 2004. no prelo.

GREGORI, Maria Filomena. Viração: experiência de meninos nas ruas. São Paulo: Companhia das Letras, 2000.

LABATE, Beatriz Caiuby; ARAÚJO, Wladymir Sena. O uso ritual da ayahuasca. Campinas: Mercado das Letras, 2002.

LE BRETON, David. Anthropologie du Corps et Modernité. Paris: PUF, 1990.

MAUSS, Marcel. As técnicas Corporais. Sociologia e Antropologia. São Paulo: Cosac \& Naify, $2003 a$.

MAUSS, Marcel. Relações reais e práticas entre a Psicologia e a Sociologia. São Paulo: Cosac \& Naify, 2003b.

PONTES, Heloísa. A burla do gênero: Cacilda Becker, a Mary Stuart de Pirassununga. Tempo Social: Revista de Antropologia da USP, São Paulo, v. 16, n. 1, p. 231-262, 2004.

RODRIGUES, Tiago. Política de drogas e a lógica de danos. Revista Verve, São Paulo, n. 3, p. 257-277, 2003.

SAHLINS, Marshall. lthas de História. Rio de Janeiro: Jorge Zahar, 2003.

SERRA, Antônio F. Norma e Criminalização. In: MACIEL, Luiz Carlos (Org.). Maconba em debate. São Paulo: Brasiliense, 1985.

SILVA, Daniela Araújo da. Do outro lado do espelho: bulimia e anorexia. 2004. Dissertação (Mestrado em Antropologia Social) - IFCH-Unicamp, Campinas.

VARGAS, Eduardo Viana. Entre a extensão e a intensidade: corporalidade, subjetivação e uso de "drogas". 2001. Tese (Doutorado em Ciências Humanas: Sociologia e Política) - FAFICHUFMG, Belo Horizonte.

VELHO, Gilberto. Nobres e Anjos: um estudo de tóxicos e hierarquia. Rio de Janeiro: Fundação Getulio Vargas, 1998.

ZALUAR, Alba. Integração Perversa: pobreza e tráfico de drogas. Rio de Janeiro: Fundação Getúlio Vargas, 2004. 